\title{
A Etnomatemática que vibra nos bebês
}

Milena Canto Sae

Thaís Essington Brown

\section{Resumo}

Que sons vibram nos corpos dos bebês? Ou que sons repicam/reciclam? Esse jogo de palavras é uma tentativa de apresentar o movimento de experimentação de sons com instrumentos confeccionados com material reciclado com crianças de oito meses a um ano e dez meses do agrupamento 1A, no Centro Municipal de Educação Infantil de Campinas, SP, CEMEI Alexandre Sartori Faria, localizada numa área de proteção ambiental (APA). Esse processo de experimentação surgiu ao pensarmos a Etnomatemática na educação infantil como produção de conhecimento aliado à cultura, considerando a criança como produtora e consumidora da cultura, onde as brincadeiras fazem parte do processo. Observamos a potência dos objetos, que denominamos "etnomatemáticos" no processo pedagógico, ao oferecermos as latas de leite do desjejum e do lanche da tarde dos bebês com colagem de suas fotos e imagem de revistas. Foi surpreendente o envolvimento, habilidade e capacidade de criação dos bebês que se divertiram com as diversas formas lúdicas, o que possibilitou a percepção de noções intuitivas de espaço e de formas, a partir de um mesmo objeto.

Palavras chave: Educação Infantil, experimentação, Etnomatemática, cultura. 


\section{Introdução}

As propostas curriculares de Educação Infantil afirmam, que deve ser assegurado às crianças, dentre outras coisas, o acesso a bens culturais. A Etnomatemática vem ao encontro desta proposta, uma vez que considera as questões relativas ao ambiente sociocultural que a criança está inserida. Além disso, há a proposta de ensinar às crianças o conhecimento matemático através de experiências de exploração e ampliação de conceitos e relações matemáticas.

No curso de "Etnomatemática e Prática Pedagógica" ${ }^{1}$ oferecido pela Rede Municipal de Educação de Campinas, no ano de 2011, ao pensarmos em como poderíamos criar algo nessa proposta com bebês, surgiu a ideia de confeccionarmos "objetos etnomatemáticos" com material existente na escola e oferecer às crianças. Surgiram os questionamentos: Que sons vibram nos corpos dos bebês? Ou que sons repicam / reciclam? Esse jogo de palavras foi uma tentativa de apresentar o movimento de experimentação de sons com instrumentos confeccionados com material reciclado com crianças de oito meses a um ano e dez meses do agrupamento 1A, no Centro Municipal de Educação Infantil de Campinas, SP, CEMEI Alexandre Sartori Faria, localizada numa área de proteção ambiental (APA).

Ferreira e Calegaro (2009) apresentam diferentes estudos relativos à matemática que já podem ser confirmados nas vivencias com crianças muito pequenas e bebês. Em um experimento com bebês de 5 a 13 meses, utilizando figuras que se moviam em trajetórias aleatórias, os resultados foram surpreendentes; os bebês realmente discriminavam a numerosidade dos conjuntos. Karen Winn (2010), pesquisadora do Laboratório de Cognição Infantil da Universidade do Arizona, acredita ainda que os bebês são também sensíveis a conjuntos de ações; usando um teatrinho de marionetes, ela mostrava repetidamente um boneco dando 2 pulos, a cada série de dois pulos o interesse do bebê diminuía. Assim que o boneco deu três pulos, o tempo de atenção do bebê no evento quase dobrou. $\mathrm{O}$ inverso foi usado como controle: 3 pulos seguidos de 2 pulos surtiam o mesmo efeito, o interesse do bebê era reavivado diante da mudança na numerosidade do conjunto de ações.

Em outro experimento investigou a percepção numérica intermodal de bebês entre 6 e 8 meses. Foram-lhes mostradas duas imagens de conjuntos, um deles com 2 objetos domésticos e outro com três, enquanto isso, os bebês ouviam uma sequência de 2 batidas de tambor. Durante as repetições, os bebês olhavam por mais tempo para o conjunto cujo número de elementos era equivalente à quantidade de batidas, como que percebendo uma equivalência abstrata entre os estímulos: a equivalência numérica como observaram Flavell e Miller \& Miller (1999).

Apesar de Calegaro e Ferreira (2009) não utilizarem o termo Etnomatemática é possível, em seu artigo, achar aspectos que se relacionam a este conceito, uma vez que defendem a ideia de que não se pode atribuir habilidades matemáticas humanas exclusivamente a fatores biológicos, apoiados nos princípios da seleção natural. A evolução deve ser considerada como uma perspectiva teórica viável para se entender o desenvolvimento cognitivo humano, porém deve-se lembrar que,

${ }^{1}$ Ministrado pela professora Maria Aparecida da Silva Damin 
para seu completo entendimento, devemos incluir igualmente influências biológicas e culturais. A natureza dotou o cérebro de cada um de nós com um Módulo Numérico cuja expansão, porém, depende de nossas habilidades individuais para aprender e usar as ferramentas matemáticas transmitidas pela cultura geral e adquiridas através de interação significativa.

A seguir apresentamos uma pequena síntese de como entendemos o conceito de infância e como nos apropriamos da Etnomatemática no processo pedagógico com os bebês.

\section{A infância}

Infância é uma etapa da vida, a primeira, o começo, que adquire sentido em função de sua projeção no tempo; o ser humano vem sendo compreendido como um ser em desenvolvimento, numa relação de continuidade entre o passado, o presente e o futuro. O fragmento de Heráclito citado por Kohan (2004) sugere que o próprio da criança não é ser apenas uma etapa, mas um reinado marcado por outra relação - intensiva com o movimento. No reino infantil que é o tempo não há sucessão nem consecutividade, mas a intensidade da duração.

A criança é produtora e consumidora da cultura e as brincadeiras ininterruptas e cíclicas, construídas e renovadas a cada minuto, oferecem, a seu modo, negação da racionalidade do mundo adulto, cuja relação tempo-espaço é diferente da relação tempo espaço da criança (SME CURRÍCULO EM CONSTRUÇÃO, 1998, p.13).

Brincar é também uma condição para explorar os objetos, usando-os, manipulandoos, pesquisando-os, e na medida em que puxam, empilham, amassam desamassam, colam, pintam, dobram... Transformam! (ibidem, p.72).

Ao considerarmos essenciais as brincadeiras no processo de desenvolvimento das crianças, percebemos que, gradativamente, os jogos infantis são permeados de representações, se no início as crianças batem os pés porque gostam de fazê-lo, em seguida se tornam mais rítmicas e dão um sentido para a experiência. Na direção de Heydebrand (1991):

[...] a própria criança é um ser que continuamente se transforma. Aquilo que é apresentado será mais condizente com sua natureza quando também ainda não for algo pronto, mas sim algo que se transforma (p.88).

Ao educador cabe interpretar os sinais que a criança dá de suas habilidades e maturidade; observando como ela explora os objetos e os interesses que manifesta. O educador perspicaz é capaz de fisgar sua atenção para estimular novas aquisições, em que a criança pode "tornar-se alguém capaz de realizar projetos e interagir de modo próprio com o meio e as pessoas, em vez de se limitar a cumprir tarefas" (OLIVA, 2009, p 31).

O brinquedo educativo tem sua finalidade definida e se destina a atividade que não pode ser confundida com o brincar, como: estimular a familiaridade com letras e números ou aprimorar a coordenação motora, mas se a criança tiver liberdade para subverter seu uso o brincar fica estabelecido. A Educação Infantil tem, sim, o objetivo de ensinar, mas não no conceito tradicional de seguir um programa criado e definido pelo professor. Sua função principal é propiciar condições para que o aprendizado aconteça por iniciativa da criança e no seu ritmo (CAMARGO, 2009, p.9). 
Considerando esses aspectos, desenvolvemos um projeto visando propiciar situações em que o aprendizado acontecesse por iniciativa da criança, em seu próprio ritmo, numa perspectiva da Etnomatemática.

\section{Reaproveitando material do cotidiano - matemática e cultura}

No cotidiano da sala de aula buscamos oferecer às crianças múltiplas experiências do contexto sociocultural em que estão inseridas, com a finalidade de lhes ensinar conhecimentos da ordem do raciocínio lógico e abstrato. Ao reaproveitar materiais do cotidiano da CEMEI, como a lata do leite consumido pelos bebês no desjejum e no lanche da tarde, construímos objetos, que denominados de "objetos etnomatemáticos".

Recolhemos 24 latas, uma para cada criança da sala e as enfeitamos com fotos das crianças e figuras de revistas como imagens de bebês, crianças, animais, casais, comidas e instrumentos musicais. Imagens relacionadas às vivências e culturas dessas crianças. Em seguida, colocamos dentro de algumas latas com tampa transparente grãos e outros objetos que produzissem diferentes sons para que as crianças experimentassem inventar no brincar. Separamos outras de tampa verde, com um par de estaca de madeira dentro, ou com sementes e outras vazias, que permitiam a colocação de objetos de diferentes formas e tamanhos.

\section{Sentir, brincar, produzir sons...}

A curiosidade das crianças ficou evidente, mesmo antes da confecção dos "objetos etnomatemáticos"; como a decoração das latas, quando estávamos apenas juntando e guardando no armário, embaixo do trocador do banheiro, elas queriam ir ao local pegá-las e bater com as mãos no fundo da lata, como se fosse um bumbo ou pandeiro, experimentando a produção de diferentes possibilidades de sons. As latas decoradas, ainda vazias, foram disponibilizadas às crianças, cada uma a sua maneira brincou com ela.

Enquanto Duda a batia no banco fazendo determinado som, César batia com a mão. Dudinha a batia no chão. Quantos barulhos diferentes e empolgantes! Crianças envolvidas e atentas naquilo que estavam fazendo. Henrique, um menino que ao ouvir música imediatamente dança, sorri e se movimenta ao som de sua própria lata.

Dimensões e formas envolvendo conceitos matemáticos ao experimentar diferentes pinhas secas, de tamanhos variados e suas relações com a lata. Clara, Duda e Haysha logo as pegaram na mão, Cesar hesitou num primeiro momento.

A professora colocou uma pinha dentro de uma lata vazia, balançou-a para chamar a atenção das crianças para o som que produzia, o que imediatamente as aguçou para fazer o mesmo e inventar outras possibilidades.

Clara queria abrir sua lata para colocar a pinha. Haysha queria segurar apenas a pinha que lhe parecia algo novo. Duda chorou, pois quando tentamos colocar sua pinha na lata não cabia. A educadora pegou outra pinha e mostrou que uma de menor tamanho caberia. 
Foram decoradas 24 latas com imagens relacionadas ao dia a dia (cultura) das crianças e com uma foto de cada criança da turma. Depois de decoradas, esses "objetos etnomatemáticos" foram disponibilizados às crianças do agrupamento $1^{\mathrm{a}}$, o que proporcionou se enxergarem nas fotos (identidade) e a perceberem conceitos matemáticos através do lúdico. Observamos diversas reações e comportamentos nas crianças ao tomarem contato com estes objetos, como descreveremos alguns a seguir:

Murilo, 1 ano e 8 meses, observou por um momento e empilhou cinco latas com muita destreza e equilíbrio. Henrique e Matheus, ambos com 1 ano e 6 meses de idade, não pensaram duas vezes ao pegarem as estacas de madeira dentro da lata e fazerem um som. João Víctor, de 8 meses, reagiu de forma diferente; sorriu ao chacoalhar o instrumento e logo o levou a boca para experimentar.

Maria Alice que tem a mesma idade de Henrique preferiu apenas olhar a lata e observar as imagens se familiarizando com o objeto.

Ryana, 1 ano e 3 meses, utilizou as mãos para produzir o som ao bater na lata.

Maria Luísa, 1 ano, brincou retirando as latas de dentro da caixa. Ao finalizar a atividade solicitamos a ajuda das crianças para guardar as latas na caixa.

Para documentar as ações das crianças registramos em fotografias e escrita as crianças experimentando os "objetos etnomatemáticos". O primeiro contato com esses objetos.... Pegar, brincar, guardar... sentir cada um.

Figura 1 - A surpresa

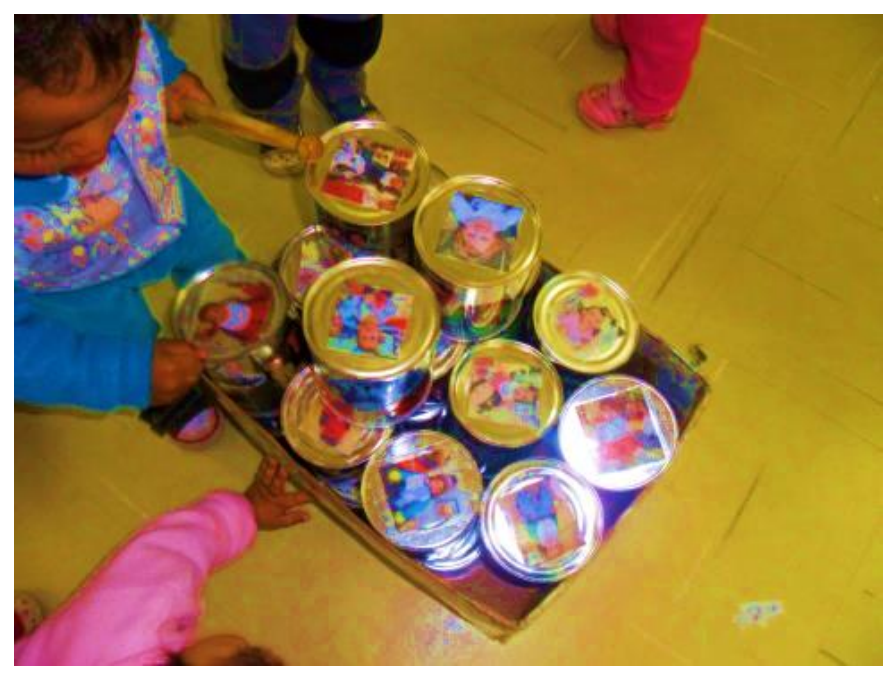

Fonte: Arquivo das autoras

Ao iniciar e finalizar a atividade houve participação e envolvimento da maioria das crianças. Elas se empolgaram ao ver a caixa cheia de brinquedos e logo queriam brincar, levar à boca, uma forma de sentir o mundo. 


\section{Identidade.... Com suas fotos nas latas de leite em pó...}

Maria Clara ao ver a foto da amiga Haysha reconheceu e apontando o dedinho disse "Haysha". A educadora mostrou para a Alice quem está na foto. Ela sorri, e aponta para sua foto.

Figura 2 - O contato
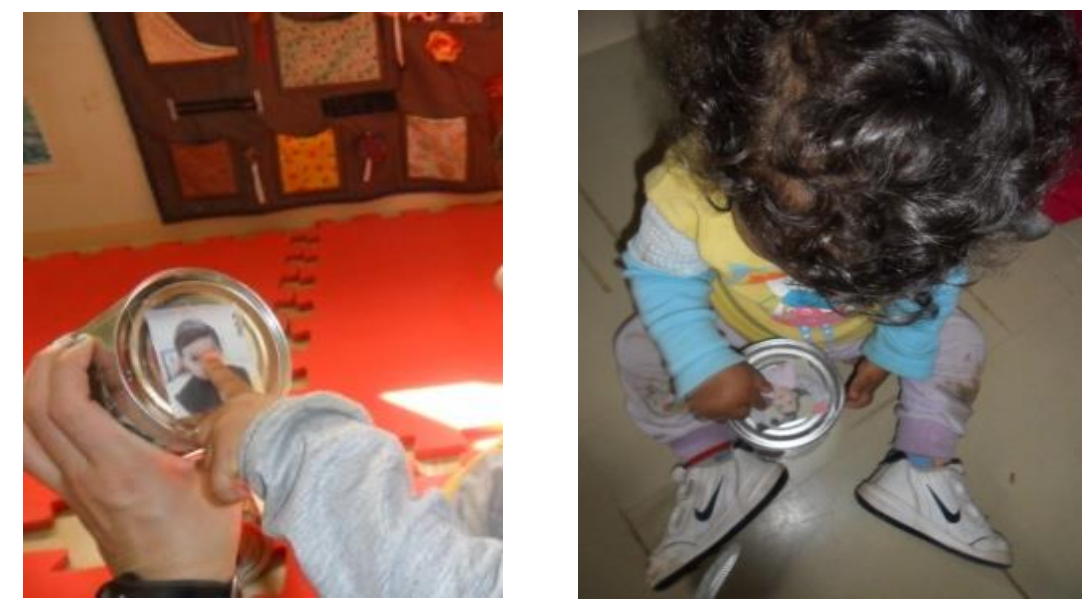

Fonte: Arquivo das autoras

César, Jhonatan, Gabi e Dudinha ficaram absortos ao se observarem na lata. Duda além de brincar com a lata achou outra utilidade, um banquinho. Ao reconhecer sua imagem na lata, sorriu e a colocou sob o braço.

\section{Instrumentos musicais...}

Maria Clara pegou a estaca para bater na lata, enquanto Ryana, Murilo e Jhonatan bateram com a mão. Maria Luisa preferiu a cuia para produzir som.

Figura 3 - A cuia

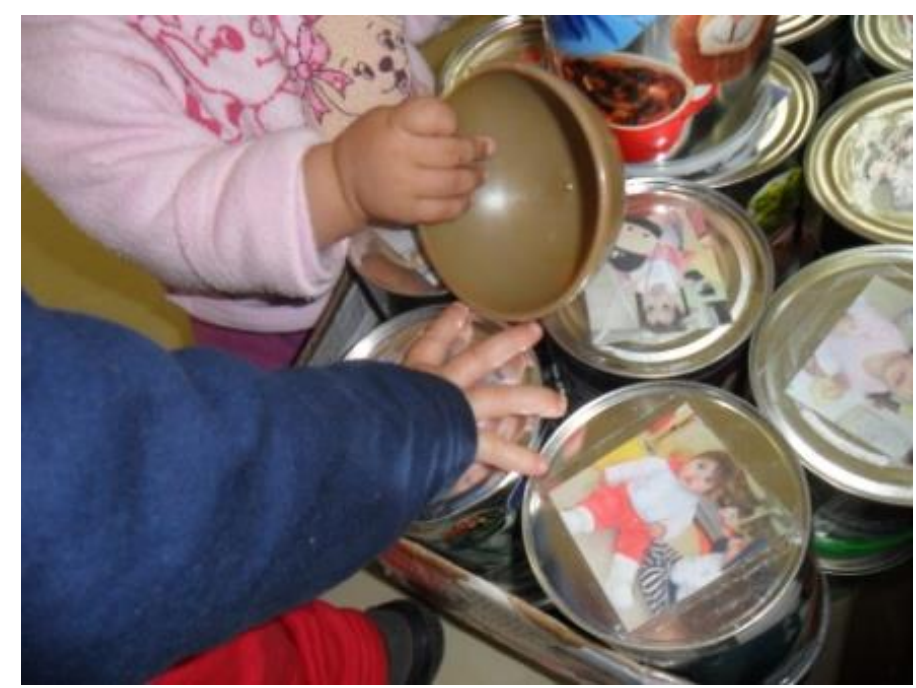

Fonte: Arquivo das autoras 


\section{Construindo a noção de forma, espaço e equilíbrio...}

César, Murilo e Lucas logo que viram os “objetos etnomatemáticos” empilharam as latas. César e Lucas, juntos, fizeram uma base para a pirâmide. Depois, alternadamente, colocavam uma lata sobre a outra. Num determinado momento já não havia mais latas próximas de Lucas, ele tirou a lata que estava na base e derrubou todo o monumento. César depois de empilhar de 3 a 4 latas vinha com a mão aberta e as derrubava, se empolgava com o barulho que as latas faziam ao cair.

Noção de dentro e fora... Henrique percebeu que dentro da lata tinha objetos que faziam barulho, abriu para ver o que era, se deparou com feijões. Retirou alguns colocou dentro da caixa de papelão e depois voltou outros na lata.

Relacionamentos interpessoais... César se interessou pela brincadeira de Henrique e tomou sua lata. Henrique reagiu chorando e apontando para o objeto tomado. Ser educadora de crianças desta idade também é ajudá-los a resolver conflitos interpessoais.

Podemos afirmar que o brincar com estes objetos possibilitou exercitar: - o sentir em cada objeto; - a noção de identidade ao se ver e aos amiguinhos nas fotos; - a noções de dentro e fora ao guardar objetos nas latas; - a percepção de tamanhos, formas, espaço e equilíbrio.

As latas decoradas com suas fotos e imagens de sua cultura, nas figuras do dia a dia das crianças, como potentes "objetos etnomatemáticos" ao se transformarem em chocalhos, bumbos, pandeiros, geraram emoção e percepção dos ritmos. Um exercício de sonhar/criar ao transformá-las em qualquer objeto da imaginação.

\section{Considerações Finais}

Exercitamos uma "postura" Etnomatemática ao disponibilizar às crianças múltiplas possibilidades de conhecimento lógico-matemático, a partir de objetos que fazem parte de seu cotidiano, de maneira lúdica, um aprendizado intenso permeado pela emoção. Processo pedagógico que exige cuidadosa observação de cada etapa, conforme a proposta curricular da Educação Infantil, em que o instrumento privilegiado de avaliação:

[...] é a observação sistemática em momentos diversificados, acompanhada de registro e análise da produção da criança constituindo-se em um procedimento básico do educador. É uma atividade processual, contínua, integral e reflete as conquistas obtidas pela criança, de acordo com a fase de desenvolvimento em que ela se encontra (SME, 2009, p. 64).

"Atividade processual" que exige do educador o papel de mediador entre a criança e o objeto de conhecimento. Este estudo mostrou o quanto as crianças apreendem nessa faixa etária. Thais Gurgel em seu trabalho defende que ao explorar objetos e ambientes variados, a criança vai montando uma representação do espaço e apreende a se orientar por pontos de referência, pois é pela ação que os bebês compreendem o entorno.

De início, os pequenos brincam com o próprio corpo - as mãos e os pés - e as roupas, que vestem como se explorassem objetos distintos. Depois, passam a manipular tudo o que veem, observando o resultado de suas ações sobre essas coisas. Quem nunca presenciou a cena de um bebê sentado em um cadeirão jogando ao chão todos os 
objetos ao seu alcance? Com isso, ele observa as diferentes consequências de seu ato: há coisas que rolam, que ficam estáticas e que pulam. Até os 3 anos, é isso o que amplia a percepção sobre o entorno (GURGEL, 2010)

Produzir “objetos etnomatemáticos” e apresentá-los às crianças do agrupamento 1A foi uma experiência enriquecedora, tanto para as educadoras que se surpreenderam com o envolvimento, habilidade e capacidade de criar dos pequenos, quanto para os bebês que se divertiram com as diversas formas lúdicas de perceber/apreender conceitos matemáticos a partir de um mesmo objeto.

Ao brincar, a percepção da matemática e de diversos saberes vai sendo formada, ao mesmo tempo em que a criança descobre o mundo, expõe suas indagações, exercita a criatividade, fantasia, imagina. O brincar como fonte de desenvolvimento em "diversos aspectos como o físico, intelectual, social, pessoal e afetivo" (FIGUEIREDO, 2008, p. 52), além do desenvolvimento de habilidades e posturas, pois é no "brincar que a criança inicia seus laços sociais” (ibidem, p. 53).

\section{Lançado à vida...}

$\begin{array}{rr}\text { Eu caminho... } \\ \text { Nasci! } & \begin{array}{r}\text { Nós caminhamos... } \\ \text { Sozinho não poderei }\end{array} \\ \text { Neste mundo cheguei, } & \text { Fazer tudo o que sonhei } \\ \text { Eis - me na escola, } & \text { Sua ajuda aponta } \\ \text { A sentir novas emoções } & \text { O rumo } \\ \text { A aprender } & \text { Do caminho... O caminhar. } \\ \text { Tu caminhas... } & \text { Milena Canto Sae } \\ \text { Mas é lógico.. } & \\ \text { Não poderei } & \\ \text { Viver esta experiência } & \\ \text { Sem a tua companhia... } & \end{array}$

\section{Referências}

CALEGARO, M. M.; SARTORIO, R.; FRAINER, J.; FERREIRA, S. N. A Psicogênese das Habilidades Matemáticas. Revista de Psicologia, $\mathrm{n}^{\mathrm{O}}$ 2, Faculdade de Ciências Sociais de Florianópolis, 2009.

CAMARGO, M. B. de C. Educação Infantil: Mapeando Vida, Espaço, Sonhos e Desejos Expressos nos Territórios dos Projetos Pedagógicos do NAED SUL, Campinas, São Paulo. Monografia apresentada ao Programa de Pós-Graduação da Faculdade de Educação da Universidade Estadual de Campinas, 2009.

FLAVELL, J. H.; MILLER, Patrícia H. \& MILLER, Scott A. Desenvolvimento cognitivo. Porto Alegre: Artmed, 1999. p. 99-110. 
FIGUEIREDO, C. D. A importância do brincar para o desenvolvimento infantil no contexto escolar. Monografia apresentada ao Curso de Psicologia da Faculdade de Ciências da Saúde - FACES do Centro Universitário de Brasília - UniCEUB, 2008.

GURGEL, T. Peça a peça, o mundo se constrói. Disponível em: http://revistaescola.abril.com.br/crianca-e-adolescente/desenvolvimento-eaprendizagem/peca-mundo-constroi-espaco-pontos-referencia-crianca-lateralidadereversibilidade-503957.shtml Acessado em 01/08/2011.

HEYDEBRAND, C. V. A Natureza anímica da criança. São Paulo: Editora Antropofísica, 1991.

KOHAN, W. O. A infância da educação: o conceito devir-criança. In: Walter Omar Kohan. (Org.). Lugares da Infância: filosofia. Rio de Janeiro: DPA, 2004, v. 1, p. 51-68.

OLIVA, L. Brincar pelo bem das crianças. Entrevista com Tizuko Morchida Kishimoto. Revista Direcional Educador, Grupo Direcional. São Paulo, 2009.

SECRETARIA MUNICIPAL DE EDUCAÇÃO DE CAMPINAS. Currículo em Construção - Educação Infantil. Campinas, 1998.

SECRETARIA MUNICIPAL DE EDUCAÇÃO DE CAMPINAS. Diretrizes Curriculares da Educação Infantil, 2009. Acesso em junho de 2011. Disponível em: www.amavi.org.br/.../educacao/.../Indicacoes_para_a_elaborao_das Diretrizes_Curriculares_Ed_Infanti_(conselheiro_Feitosa).pdf

WINN, K. Bebês sabem diferenciar o certo e o errado? Entrevista. Disponível em: http://www.portalfiel.com.br/noticias/1116-bebes-sabem-diferenciar-o-certo-e-oerrado.html

\section{Biografia Resumida}

Milena Canto Sae. Graduação em Psicologia pela Pontifícia Universidade Católica de Campinas (2008). Pós-graduação lato sensu em Psicanálise, Grupalidade e Intervenções nas Instituições: Teoria e Técnicas Psicoterapêuticas (CEFAS-2015). Pós-graduação lato sensu em Psicologia Educacional e Saúde Mental (CEFAS-2014). MBA em Gestão Estratégica de Pessoas (Universidade Estácio de Sá-2016). Atualmente é Psicóloga Clínica - Clínica Terzis e Agente de Educação da Prefeitura Municipal de Campinas, no Centro Municipal de Educação Infantil - CEI Maria Aparecida Vilela Gomes Júlio.

Contato: milenacantosae@gmail.com

Thaís Essington Brown. Graduação em Ecologia pela Universidade Estadual Paulista (2007). Agente de Educação da Prefeitura Municipal 
Com a Palavra o Professor, Vitória da Conquista (BA), v. 2, n. 2, maio - agosto/ 2017

de Campinas, no Centro Municipal de Educação Infantil - CEI Eduardo Pereira Almeida.

Contato: thais_essington@yahoo.com.br 